\title{
Improving the odds? How to pick the winner of the English Derby
}

\author{
D.J. Marlin', J.M. Williams ${ }^{2}$ and T. Parkin ${ }^{3}$ \\ 'David Marlin Consulting Ltd., P.O. Box 187, Newmarket, Suffolk, CB8 1BA, United Kingdom; ${ }^{2}$ Centre for Performance in Equestrian Sports, \\ UWE Hartpury, Hartpury College, Gloucester, GL193BE, United Kingdom; ${ }^{3}$ Boyd Orr Centre for Population and Ecosystem Health, Institute \\ of Comparative Medicine, Faculty of Veterinary Medicine, University of Glasgow, G61 1QH, United Kingdom; dm@davidmarlin.co.uk
}

Received: 25 May 2010 / 28 May 2010

RESEARCH ARTICLE / SHORT COMMUNICATION

(c) 2014 Wageningen Academic Publishers

\begin{abstract}
Many consider the English Derby on Epsom Downs to be 'The Blue Riband of the Turf'. The Epsom Derby has been run annually since 1780 and the colt Diomed was the first winner. Today the Epsom Derby, run over 1.5 miles, is one of five classic races and is the second leg of the English Triple Crown, preceded by the 2,000 Guineas and followed by the St Leger. The prize money for 2010 has been in excess of $£ 1.25$ million. To the best of our knowledge, whilst epidemiological techniques have previously been applied in an attempt to identify risk factors for injury, the purpose of the present study, which we believe is unique, was to use an epidemiological approach to analyse factors that may be predictive of success (or failure) in a single race over the course of a number of consecutive years: The Epsom Derby. Information on the horses competing in the last 22 runnings of the Epsom Derby between 1988 and 2009. Univariate and multivariable single-level and mixed effects logistic regression models were developed using winning the Epsom Derby as the dependent variable. Between 1988 and 2009 in 22 runnings of the Derby, a total of 344 horses started the Epsom Derby. The number of runners in the race has varied between 12 and 25 over the same time period. On average the probability of winning the Derby between 1988 and 2009 was approximately $6 \%$ (22/344), without accounting for any potentially predictive variables. Variables that were related to an increased chance of success were being the favourite (odds ratio (OR) 4.75; $95 \%$ confidence interval (CI) $1.58-14.3 ; P=0.006$ ), the number of 2-year old wins (OR 1.45; CI 1.03-2.04; $P=0.03$ ), being foaled in Ireland (OR 2.80; CI 1.12-7.04; $P=0.041)$ and having the same jockey in all races throughout the horses career up to and including the Derby (OR 2.53; CI 1.0-6.41; $P=0.05)$. The highest predictive probability was for horses that started the race as a favourite, were Irish bred, had been ridden by a single jockey and had won twice as a 2-year old. Although the point estimate for this probability was $52 \%$ the degree of uncertainty around this estimate was wide, i.e. the $95 \%$ CI was 17.5 to $86.5 \%$. Nevertheless even at the lower confidence interval this still represents a significant improvement on the approximately $6 \%$ chance of picking a winner at random. In conclusion, using mixed effects logistic regression models would allow one to improve the odds of picking the winner of the Epsom Derby over the past 22 runnings.
\end{abstract}

Keywords: epidemiology, performance, horseracing, Thoroughbred, racehorse

\section{Introduction}

The word 'Derby' is used to signify a supreme race in many countries, including the Kentucky Derby, Australian Derby, German Derby and the Hong Kong Derby, but many consider the English Derby on Epsom Downs to be 'The Blue Riband of the Turf'. Races are believed to have been held on the Epsom Downs, the home of the English Derby, from the mid- $17^{\text {th }}$ Century. After the fall of the
Commonwealth, the first recorded race meeting on Epsom Downs took place on the $7^{\text {th }}$ March 1661 at which King Charles II was reported to have been present. The $12^{\text {th }}$ Earl of Derby acquired a house on the edge of Epsom, known as The Oaks and in 1779 a race for three-year old fillies named 'The Oaks' was run for the first time. The following year (1780) a race for colts and fillies over 1 mile was introduced. Legend proposes that Sir Charles Bunbury was dining with the Earl of Derby at The Oaks and a coin was tossed 
to decide if the race should be called 'The Derby' or 'The Bunbury'. Although the Earl of Derby won the toss of the coin, Sir Charles Bunbury's horse won the race with the colt, Diomed. In 1784 the distance of The Derby was increased to 1.5 miles and has remained so since that day. Today The Derby is one of five classic races and is the second leg of the English Triple Crown, preceded by the 2,000 Guineas and followed by the St. Leger. The prize money for 2010 will be in excess of $£ 1.25$ million.

Success in Thoroughbred racing is heavily centred on breeding, with top stallions commanding impressive stud fees to cover mares; artificial insemination being prohibited. Some early studies suggested a high heritability of performance in racehorses (Field and Cunningham, 1976; Hintz, 1980). However, more recent studies of the heritability of performance in racing events have demonstrated a relatively low probability of performance characteristics being passed on from sire and dam to their offspring when a single generation are considered (Williham and Wilson, 1991; Mota et al., 2005; Thiruvenkadan et al., 2005). Proudman et al. (2004) previously applied epidemiological techniques in an attempt to identify factors associated with horses falling in the Grand National steeplechase race run at Aintree, UK, annually. However, to the best of our knowledge, epidemiological techniques to identify factors associated with horses winning races have not previously been reported.

A number of studies have attempted to use single or multiple variables such as velocity at a heart rate of 200 beats per minute (V200) or velocity at a blood lactate of $4 \mathrm{mmol} / \mathrm{l}$ (VLA4) to predict race performance over the course of a season or career, for example by relating these variables to earnings (e.g. Harkins et al., 1993; Lindner, 2010). However, the purpose of the present study, which we believe is unique, was to use an epidemiological approach to analyse factors that may be predictive of success (or failure) in a single race over the course of a number of consecutive years: The Epsom Derby.

\section{Materials and methods}

Information on the horses competing in the last 22 runnings of the Epsom Derby between 1988 and 2009 was collected from The Racing Post website (www.racingpost. com) and other internet resources, including trainer and stud websites. This included: sire, dam, sire grand-sire, sire grand-dam, dam grand-sire, dam grand-dam, date of foaling, location of foaling (geographic), stud foaled at/ breeder, foal number, price at sales (if sold), date of first race, age at first race, racing career performance preceding the Derby, number of jockeys in career, number of trainers in career, location of stable (geographic), whether the horse had raced in a Derby trial, the age of the trainer, the sex of the trainer, the number of years in training, the number of horses in training, the distance travelled to Epsom, the draw on the track, the jockey, the official rating $(\mathrm{OR})$ at the time of the Derby and the starting price. Further variables were calculated in order to represent a change in form from the 2-year old season to 3-year old season.

\section{Statistical analysis}

Univariate and multivariable single-level and mixed effects logistic regression models were developed using winning the Epsom Derby as the dependent variable. Several variables such as sire, dam, sire grand-sire, sire grand-dam, dam grand-sire, dam grand-dam, trainer, training location and breeder were included as random effects to assess for clustering at these levels. However, none of these random effects were significant. All fixed effects variables with a $P$-value of $\leq 0.25$ during the univariate screening process were available for inclusion in the final multivariable model. Mixed effects multivariable logistic regression models were developed, using a forward selection procedure. Variables with strong a priori biological reasons for inclusion were also considered in the final model and biologically plausible interaction terms were investigated. Variables were retained in models if they significantly reduced the residual deviance of the model (likelihood ratio statistic; $P<0.05$ ).

The fit of the final multivariable model was assessed using the Hosmer-Lemeshow goodness-of-fit test (Hosmer and Lemeshow, 2000). Covariate patterns with the greatest leverage, delta betas, delta $x^{2}$ and delta deviance values were identified. Individual observations with these covariate patterns were identified and removed from the models and the change in the value of the coefficients was reassessed (Hosmer and Lemeshow, 2000). The predictive ability of the single level model was determined by generating a receiver operating characteristic (ROC) curve. Predictive probabilities (including $95 \%$ confidence intervals $((95 \% \mathrm{CI}))$ for each of 34 different covariate patterns contained within the final multivariable model were calculated. All models were built using STATA version 10.0 (College Station, TX, USA).

\section{Results}

Between 1988 and 2009 in 22 runnings of the Derby, a total of 344 horses started the Epsom Derby. The number of runners in the race has varied between 12 and 25 over the same time period. On average the probability of winning the Derby between 1988 and 2009 was approximately 6\% (22/344), without accounting for any potentially predictive variables. Table 1 shows that over the past 22 running's of the Derby, variables that were related to an increased chance of success were being the favourite, the number of 2-year old wins, being foaled in Ireland and having the same Jockey in all races throughout the horses career up to and including the Derby. 
Table 1. Multivariable logistic regression model of factors associated with the likelihood of winning the Epsom Derby.

\begin{tabular}{|c|c|c|c|}
\hline Variable & $\begin{array}{l}\text { 음 } \\
\text { 힝 } \\
\text { 응 }\end{array}$ & 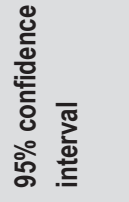 & 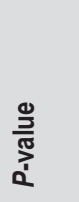 \\
\hline Being the favourite & 4.75 & $1.58-14.3$ & 0.006 \\
\hline Number of 2-year old wins & 1.45 & $1.03-2.04$ & 0.03 \\
\hline Foaled in Ireland & 2.80 & $1.12-7.04$ & 0.041 \\
\hline One jockey throughout career to date & 2.53 & $1.0-6.41$ & 0.05 \\
\hline
\end{tabular}

Horses that started the race as favourite were 4.75 times more likely to win the race than those that did not start the race as favourite. For each extra win as a two-year old the likelihood of winning the Epsom Derby increased by 1.45 times. Horses that were foaled in Ireland were 2.8 times more likely to win the race than horses foaled elsewhere. Horses that had only ever been ridden by one jockey throughout their career up to and including the Derby were 2.53 times more likely to win the race than horses that had been ridden by multiple jockeys.

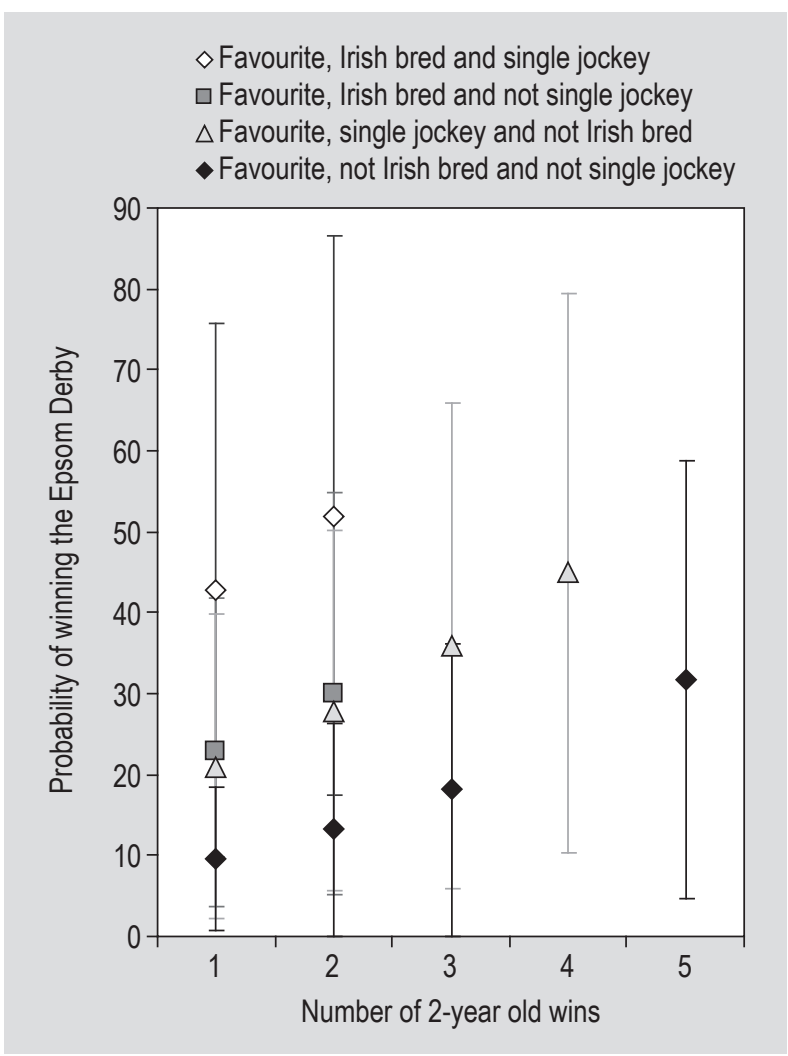

Figure 1. Plot of the predictive probabilities for each covariate pattern derived from the final multivariable logistic regression model that included being the favourite for the Epsom Derby (showing 95\% confidence intervals).
The predictive probabilities for each covariate pattern derived from the final multivariable logistic regression model ranged from the lowest (1.5\%) for a horse that was not the favourite, had no wins going into the Epsom Derby, was not Irish bred and had been ridden by more than one Jockey in its career, up to a predictive probability of $52 \%$ for a horse that was favourite, Irish bred, had won twice as a 2-year old and had been ridden by a single Jockey throughout its career.

Figure 1 shows the predictive probability of winning the Epsom Derby for each of 12 covariate patterns derived from the final multivariable logistic regression model that included being favourite for the Epsom Derby. For example, the probability of a win for a horse that was favourite, Irish bred, had only ever had one jockey and had won twice as a 2-year old win was $52.0 \%(95 \% \mathrm{CI}=17.5-86.5)$, whereas the probability of a win for a horse that was favourite, not Irish bred, had been ridden by more than one jockey and had won five times as a 2-year old was 31.8\% (95\% CI $=4.8-58.8)$.

Figure 2 shows the predictive probability of winning the Epsom Derby for each of the 12 covariate patterns derived from the final multivariable logistic regression model that included being Irish bred. For example, the probability of a

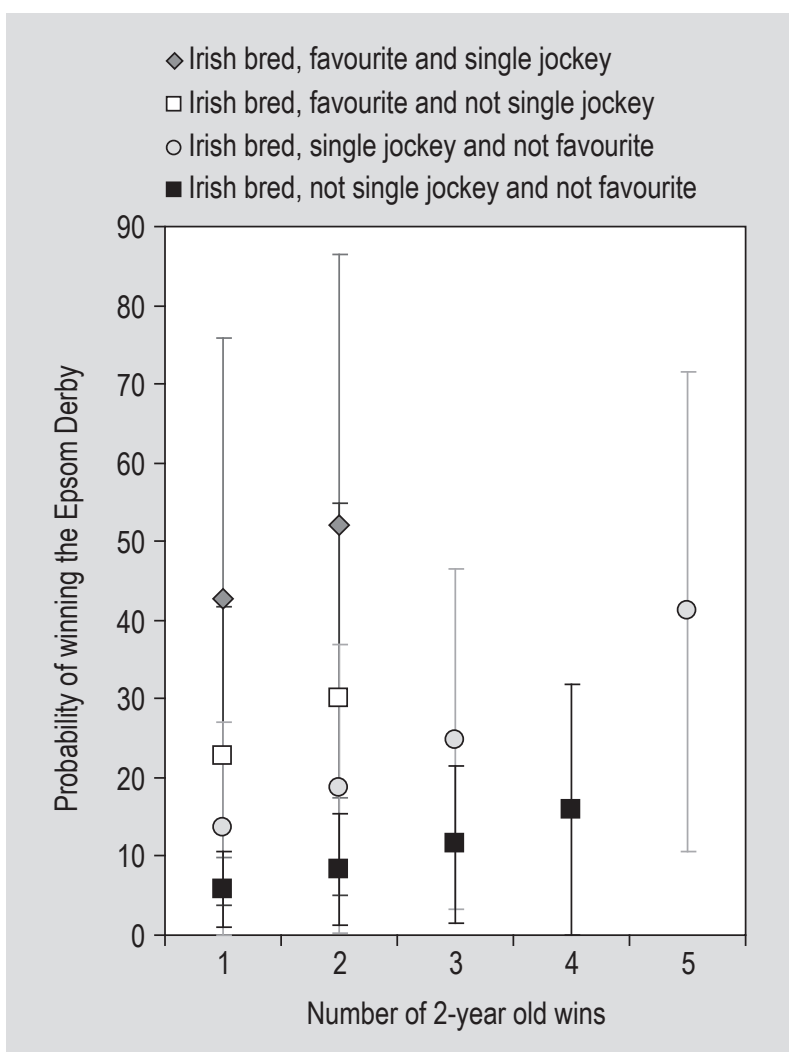

Figure 2. Plot of the predictive probabilities for each covariate pattern derived from the final multivariable logistic regression model that included being Irish bred (showing $95 \%$ confidence intervals). 
win for a horse that was Irish bred, favourite for the Epsom Derby, had been ridden by more than one jockey and had won twice as a 2-year old win was 30.0\% (95\% CI $=5.1$ 54.9) whereas the probability of a win for a horse that was Irish bred, not favourite, had been ridden by more than one jockey and had won three times as a 2 -year old was $11.6 \%$ (95\% CI = 1.6-21.6).

\section{Model diagnostics, goodness of fit and predictive ability}

The final multivariable model was not significantly affected by influential covariate patterns. The HosmerLemeshow goodness-of-fit statistic indicated that there was no evidence that the final model did not fit the data well $(P=0.53)$. The model was therefore considered to be reasonably calibrated. The predictive ability of the model, as measured by the area under the ROC curve, was $78 \%$ or 'good' (Hosmer and Lemeshow, 2000).

\section{Discussion}

Epidemiology is a powerful approach that can be used to investigate complex, confounding and non-apparent or counter-intuitive relationships in large datasets. Epidemiological techniques have been used in a number of different racehorse related studies ranging from identifying risk factors for injury in training (Lam et al., 2007; Parkin et al., 2004; Perkins et al., 2005; Verheyen et al., 2006) to falls in jump racing (Pinchbeck et al., 2004). However, to the best of our knowledge this is the first published use of epidemiology to identify factors associated with racing success.

Potential limitations of this study include a lack of power to identify significant factors associated with the outcome. This study was only able to collate data related to so many potential variables from a relatively small number of races (22 races since 1988). However, many aspects of racing have changed significantly over the last thirty to forty years and restricting the dataset to only include more recent races has the potential advantage of making the findings more representative and applicable to current and future Epsom Derby races. As one of the aims of this paper was to identify predictive probabilities for future races for different covariate patterns we felt that using data from these more recent races was the most appropriate strategy. The potential lack of power and resultant increased uncertainty is represented in the plots by the relatively wide $95 \%$ confidence intervals around the individual point estimates.

As expected, being the favourite for the race was significantly associated with the likelihood of winning the Derby. Favourites were 4.8 times more likely to win than other horses in the race. This finding is not surprising as there is an enormous amount of man-power and analytical time directed at identifying the correct starting prices for runners, particularly in high-profile races such as the Derby. This variable is a composite summary measure of a lot of race analyses conducted by the betting industry. What is interesting is that even when accounting for this strongly associated variable there are other variables that remain as being associated with the outcome.

The number of wins as a 2-year old was significantly associated with the likelihood of winning the Derby. Each race won as a 2-year old increased the likelihood for winning the Epsom Derby by 1.5 times. Thus, a horse with four wins as a 2-year old would be 5 times $\left(1.5^{4}\right)$ more likely to win the Epsom Derby than a horse that had not won any two-year old races. Interestingly, the number of races won as a 3-year old (The Epsom Derby is a race for 3-year old colts or fillies only) was not predictive of success in the Epsom Derby. At face value this is surprising as there are a number of races for 3-year olds that are run in the UK between April and late May (e.g. the Sandown Classic Trial, the 2000 Guineas, the Chester Vase, the Dante Stakes and the Predominate Stakes). However, as trainers of horses entered in the Epsom Derby may intentionally try to avoid direct competition before the Derby itself, then the lack of a positive association may be understandable.

It may also be that these 'Derby trial' races are not good indicators of performance over the Derby distance (1 mile and 4 furlongs; $2.41 \mathrm{~km}$ ) as they are run over shorter distances. For example, the 2000 Guineas which is the first classic of the season and is held in late April or Early May is a Group 1 race run over 8 furlongs $(1.61 \mathrm{~km})$; 4 furlongs shorter than the Derby distance. Another reason why Derby trials may not be a strong predictor of Derby success is the difference in the tracks themselves. For example, the Derby course is a left-handed U-shaped course which undulates and has a tight turn into the finishing straight. By contrast, Chester is flat, left-handed and considered to be the smallest and tightest course in the UK with the horses running on the turn for virtually the whole race and the 2000 Guineas run at Newmarket on the Rowley mile course is right handed with an uphill finish. Another possibility is that the horses running in the Derby trial races are not at maximal fitness and that these early 3 -year old races are used to ensure that the horse peaks for the Epsom Derby or that tactics are being employed to ensure the horses true ability is not apparent.

Being foaled in Ireland increased the likelihood that a horse would win the Epsom Derby by 2.5 times over being foaled elsewhere. This observation is not related to more Irish bred horses entering the Epsom Derby as this effect was accounted for in the analysis. It is also not due to prominent Irish trainers such as O'Brien and $\mathrm{Ox}$ ) and their success in recent years as there are a number of UK trained, Irish bread winners. However, this interesting finding could relate to early management of the foal and yearling whether it be 
in terms of nutrition or exercise. And that this opens up an interesting area for future research that has not really been investigated to any great extent.

Having the same jockey in all races up to and including the Epsom Derby increased the likelihood of winning the Derby by 2.5 times. Unlike human sport, racing involves the relationship between two athletes. The horse provides the movement but the jockey makes decisions concerning tactics. Similarly, a jockey that can calm and or control a strong, difficult or anxious horse might reasonably be expected to obtain a superior performance. A jockey who has ridden a horse in all its career races would be expected to develop either a better rapport or understanding with an individual horse. Breeding was not found to be significantly associated with the likelihood of winning the Epsom Derby. Certain bloodlines appeared to be associated with an increased likelihood of a horse winning the Epsom Derby but when an adjustment was made for the number of progeny within the population, this effect disappeared.

The predictive probabilities calculated for each covariate pattern included in the final model indicate that it may be possible to identify horses that are significantly more likely to win the Epsom Derby. The highest predictive probability was for horses that started the race as a favourite, were Irish bred, had been ridden by a single jockey and had won twice as a 2-year old. Although the point estimate for this probability was $52 \%$ the degree of uncertainty around this estimate was wide, i.e. the $95 \%$ CI was $17.5 \%$ to $86.5 \%$. Nevertheless even at the lower confidence interval this still represents a significant improvement on the approximately $6 \%$ chance of picking a winner at random. The predictive probability associated with being a favourite (not accounting for any other variables) was $24 \%$.

Examining entries for the 2010 Epsom Derby, the current Irish bred favourite with three 2-year old wins and a single jockey throughout his career would also possess the highest predictive probability from our model. However, there are a few notable differences in the ranking of the current betting and the ranking based on the predictive probabilities from our model. For example, the Irish bred 'At First Sight', with one 2-year old win and a single jockey through his career is predicted by our model to do better than the betting would suggest. Other horses such as 'Midas Touch' are predicted by our model to do worse than the current betting suggests. ${ }^{1}$ It is however important to note that the $95 \%$ confidence intervals around all of the individual covariate pattern point estimates of predictive probability are wide, implying that there is a high degree of uncertainty about these predictions.

\section{Conclusions}

The highest predictive probability for horses winning the Epsom Derby over the past 22 runnings was for horses that started the race as a favourite, were Irish bred, had been ridden by a single jockey and had won twice as a 2-year old. Although the point estimate for this probability was $52 \%$ the degree of uncertainty around this estimate was wide, i.e. the $95 \%$ CI was 17.5 to $86.5 \%$. Nevertheless even at the lower confidence interval this still represents a significant improvement on the approximately $6 \%$ chance of picking a winner at random. In conclusion, using mixed effects logistic regression models would allow one to improve the odds of picking the winner of the Epsom Derby.

\section{References}

Field, J.K. and Cunningham, E.P., 1976. A further study of the inheritance of racing performance in thoroughbred horses. Journal of Heredity 67: 247-248.

Harkins, J.D., Beadle, R.E. and Kamerling, S.G., 1993. The correlation of running ability and physiological variables in thoroughbred racehorses. Equine Veterinary Journal 25: 53-60.

Hintz, R.L., 1980. Genetics of performance in the horse. Journal of Animal Science 51: 582-594.

Hosmer, D.W. and Lemeshow, S., 2000. Applied logistic regression. $2^{\text {nd }}$ edition. John Wiley and Sons Inc., New York, NY, USA.

Lam, K.K., Parkin, T.D., Riggs, C.M. and Morgan, K.L., 2007. Evaluation of detailed training data to identify risk factors for retirement because of tendon injuries in Thoroughbred racehorses. American Journal of Veterinary Research 68: 1188-1197.

Lindner, A.E., 2010. Relationships between racing times of Standardbreds and v4 and v200. Journal of Animal Science 88: 950-954.

Mota, M.D., Abrahão, A.R. and Oliveira, H.N., 2005. Genetic and environmental parameters for racing time at different distances in Brazilian Thoroughbreds. Journal of Animal Breeding and Genetics 122: 393-399.

Parkin, T.D., Clegg, P.D., French, N.P., Proudman, C.J., Riggs, C.M., Singer, E.R., Webbon, P.M. and Morgan, K.L., 2004. Horse-level risk factors for fatal distal limb fracture in racing Thoroughbreds in the UK. Equine Veterinary Journal 36: 513-519.

\footnotetext{
${ }^{1}$ Postscript by the authors: The winner of the 2010 Epson Derby was 'Workforce' (starting price 6-1), a British Thoroughbred racehorse ridden by Ryan Moore in a course record time. In 2009 he had won one race and in 2010 he also won the Prix de l'Arc de Triomphe, both times ridden by the same jockey. In a career that lasted from September 2009 until October 2011, 'Workforce' ran nine times and won four races before being retired to stand as a breeding stallion in Japan. 'At First Sight', a 100-1 outsider who had been universally dismissed as only being a pacemaker, was beaten into $2^{\text {nd }}$ place by 7 lengths. 'At First Sight' lead the race from the start and was only eventually overtaken just over 1 furlong from the finish by 'Workforce. 'Rewilding' was $3^{\text {rd }}$ (starting price 9-2), the favourite 'Jan Vermeer' was $4^{\text {th }}$ and 'Midas Touch' was $5^{\text {th }}$.
} 
Perkins, N.R., Reid, S.W. and Morris, R.S., 2005. Risk factors for injury to the superficial digital flexor tendon and suspensory apparatus in Thoroughbred racehorses in New Zealand. New Zealand Veterinary Journal 53: 184-192.

Pinchbeck, G.L., Clegg, P.D., Proudman, C.J., Morgan, K.L. and French, N.P., 2004. Case-control investigation of the factors affecting the risk of horses falling during steeplechase racing in the UK. Veterinary Record 155: 11-15.

Proudman, C., Pinchbeck, G., Clegg, P. and French, N., 2004. Equine welfare: risk of horses falling in the Grand National. Nature 428: 385-386.
Thiruvenkadan, A.K., Kandasamy, N. and Panneerselvam, S., 2009. Inheritance of racing performance of Thoroughbred horses. Livestock Science 121: 308-326.

Verheyen, K., Price, J., Lanyon, L. and Wood, J., 2006. Exercise distance and speed affect the risk of fracture in racehorses. Bone 39: 1322-1330.

Willham, R.L. and Wilson, D.E., 1991. Genetic predictions of racing performance in quarter horses. Journal of Animal Science 69: 3891-3894. 